\title{
The Responsiveness of ODL Services to the Needs of Students with Disabilities at Zimbabwe Open University: The Case of Harare Region.
}

\author{
Mr Lincoln Hlatywayo, Mr Andrew Mukono \\ Senior Lecturer: Zimbabwe Open University \\ Lecturer: Zimbabwe Open University
}

\begin{abstract}
Prior to the inception of the Zimbabwe Open University (ZOU) very few students with disabilities were able to be accommodated in the available conventional universities due to a number of limitations. It must therefore follow that the introduction of Open and Distance University education by ZOU should have seen an increase in opportunities for admission of students with disabilities in the university. This research interrogates the inclusiveness of ZOU's ODL services to students with disabilities twelve years after inception. This research employed the qualitative approach underpinned by the descriptive survey design. It sought to answer questions such as, are students with disabilities realizing their full potential through ODL? Structured interviews were used for data gathering purposes. Out of e total of 21 students with disabilities at the region a total of 20 were interviewed. A typological and logical analysis of data was carried out. The results indicated that ZOU, Harare Region is not very responsive to the needs of all students with disabilities as it enrolls very few such students. While the students support services unit tries its level best to assist students with disabilities results showed that the university needs to do a lot in processes such as registration, tutorials, assignments and examinations .Recommendations made include the need to increase accessibility to the regional offices and to adapt the environment by putting ramps for wheelchair users. It was also recommended that special considerations be done in marking work of students with disabilities.
\end{abstract}

Key words: Students with disabilities, accessibility, adaptations, inclusion

\section{Introduction}

In Zimbabwean society people living with disabilities have often been left on the peripheries of society. This is largely steeped in the traditional belief that being disabled was punishment from the gods hence people with disabilities were evidence that someone or some people in their respective clans had erred. As such disabled people were an abomination to the soil, a disgrace or curse often treated with contempt (Dube and Charowa 2005). Today people living disabilities suffer the stigma that is steeped in such traditional beliefs.

The traditional education system did not spare the disabled as schools and facilities were separately set up away from their able bodied counterparts (Sayini and Goyal 2009). This means people living with disabilities were excluded and lived separate lives unlike today where efforts are being made to include such individuals in mainstream society. The politics of exclusion have not been internalised by the able bodied people alone (who still regard people with disabilities as different socially and intellectually) but by the disabled people themselves. Many have given up to their 'doomed' fate and therefore do not see opportunities as they come especially in education. Theirs is a defeated battle alongside the able bodied counterparts.

To start with, who are the people living with disabilities? The World Health Organisation defines disability as 'any restriction or lack of ability to perform an activity in a manner or within a range considered normal for a human being' (WHO, 1996)' (Cited by Choruma ) The 1982 National Disability Survey of Zimbabwe also came up with a working definition of disability as 'a physical or mental condition, which makes it difficult or impossible for the person concerned to adequately fulfil his or her normal role in society' (Zimbabwe Department of Social Services, 1982, p8- Cited by Choruma ). According to the Disabled Persons Act [Chapter 17:01] of Zimbabwe " "disabled person" means a person with a physical, mental or sensory disability, including a visual, hearing or speech functional disability, which gives rise to physical, cultural or social barriers inhibiting him from participating at an equal level with other members of society in activities, undertakings or fields of employment that are open to other members of society...' The Zimbabwe Open University has such students amongst its student population.

The term 'students living with disabilities' has been used in this paper to mean students with transient or permanent disabilities as well as physical, sensory and mental disabilities. The term is used interchangeably with students with special needs. 
However it is a fact that students with disabilities often experience limited access to and success within postsecondary education programs, which subsequently limits their employment (Stodden et al 2001). The UNESCO Salamanca Statement (1994) calls on all governments to give the highest priority to inclusive education and the UN Convention on the Rights of Persons with Disabilities (2006) calls on all States Parties to ensure an inclusive education system at all levels Around the world, people living with disabilities constitute 10 $\%$ (650 million) and they are the world's largest minority and $80 \%$ of these live in developing countries (http://www.un.org/disabilities/default.asp?id=1561). This is commensurate with statistics in Zimbabwe where the population of people with disabilities is estimated to be slightly more than $10 \%$ of the total population (Dube and Charowa 2005). It is also true that people living with disabilities constitute the vulnerable and have often lived on the margins in societies due to limited opportunities that have been availed to them (Gwitimah and Khupe 2008). Twenty percent of the world's poorest are the disabled and it is therefore not surprising that the global literacy rate for adults with disabilities is as low as 3 per cent (http://www.un.org/disabilities/default.asp?id=1561). Consequently unemployment among the disabled is as high as 80 per cent in some countries and one Shekhar (2009) has pointed out that disability and poverty are often intertwined.

The Harare Regional Centre of the Zimbabwe Open University has a student population of 3122 and of these 21 have disabilities. This means students with disabilities constitute $0.67 \%$ of the total population against WHO standards of $10 \%$ in any given population. This is a disappointing figure considering the fact that ZOU as an institution is opening up opportunities for people living with disabilities. The Zimbabwe Disability Act (1996:) clearly stipulates that it 'aims to achieve equal opportunities for disabled persons by ensuring, so far as possible, that they obtain education and employment, participate fully in sporting, recreation and cultural activities and are afforded full access to community and social services...' However the statistics of students with disabilities are not all encompassing as some of the students with disabilities do not declare their status for fear of the stigma and exclusion as stated above.

In line with the International day of people living with disabilities - 3 December 2011 whose theme was "Together for a better world for all: Including persons with disabilities in development", people living with disabilities become crucial in a world that is also bent on poverty and hunger eradication- both of which are targets of the UN's Millennium Development Goals. The Zimbabwe Open University therefore recognizes the relevance of offering equal opportunities to all in terms of education and people living with disabilities therefore fall within the student population of the ZOU. This paper thus is timeous as it attempts at revisiting and evaluating the role played by the Zimbabwe Open University at bringing education to everyone's doorstep. Currently the Zimbabwe Open University has made in roads in sign language, that is teaching basic sign language, where students who wish to be literate in the language can enrol for a short course. This is aimed at expanding as well as including people with hearing impairment as well as those wishing to draw closer to them in the ZOU family. This paper therefore interrogates the extent to which ZOU has brought opportunities to people living with disabilities, how are they being serviced, areas of improvement as well as innovations.

\subsection{Statement of the Problem}

Zimbabwe is ranked as having the highest literacy rate in Africa of over $90 \%$. There are no statistics that prove the inclusion of people with disabilities in these literacy figures. There are 15 universities in the country but very little research has been carried to ascertain the responsiveness of higher education to the needs of students with disabilities. This research study sought to answer the question "how responsive are the Zimbabwe Open University Services to the needs of students with disabilities?"

\section{Methodology}

This study adopted the use of mixed methodology. The research questions were designed in the way that they require qualitative responses. However, some questions which were derived from the research questions demanded quantitative presentation and analysis. These were based on the responses gathered from the respondents. Johnson and Onwuegbuzie (2004) define mixed methods research as the class of research where the researcher mixes or combines quantitative and qualitative research techniques, methods, approaches, concepts or language into a single study or set of related studies. Rossman and Wilson (1985) cited by Johnson et al. (2007) identified three reasons for combining quantitative and qualitative research that is to enable confirmation or collaboration of each other through triangulation, to develop analysis in order to provide richer data and to initiate new modes of thinking by attending to paradoxes that emerge from the two data sources. In this study both qualitative and quantitative data were collected concurrently and then analyzed using both qualitative and quantitative data analysis methods.

The research design adopted for this study was the case study (ZOU, Harare region). Yin (1993) defines a case study is a detailed investigation of a single individual or group. Case studies can be qualitative or quantitative in nature, and often combine elements of both as was in the current study. The defining feature of a 
case study is its holistic approach; it aims to capture all of the details of a particular individual or group, which were relevant to the purpose of the current study, within a real life context, (Yin, 1993). The case study allowed the researcher to explore all three domains of the respondents, which are cognitive, behavioral and affective, (Leedy, 1980). This helped in bringing out the inner feelings of the respondents. The design was also used because of the characteristics as noted by Borg and Gall (2007). They noted that the case study is a design which serves three purposes. First to produce detailed descriptions of the issue under study. Secondly, to develop possible explanations and thirdly to produce possible evaluations.

\section{Findings}

The results are presented basing on the responses to the processes on the research instrument. Demographic characteristics of the respondents are given first.

\subsubsection{Biographic Data}

Table1: Distribution by Type of Disabilities

\begin{tabular}{|l|c|c|}
\hline Disability type & No & \% \\
\hline Physical & 5 & 20 \\
\hline Visual & 1 & 5 \\
\hline Hearing & 1 & 5 \\
\hline Albinism & 2 & 10 \\
\hline Mental & 1 & 5 \\
\hline Height & 1 & 5 \\
\hline Obesity & 2 & 10 \\
\hline Epilepsy & 2 & 10 \\
\hline Health related eg. heart problems & 2 & 10 \\
\hline Learning & 3 & 10 \\
\hline \multicolumn{1}{|c|}{ Total } & $\mathbf{2 0}$ & $\mathbf{1 0 0}$ \\
\hline
\end{tabular}

\section{Comment}

The biographic data shows that the university (Harare Region) enrolls students with diverse disabilities with the majority being those with physical disabilities

Table 2: Distribution by Gender

\begin{tabular}{|l|c|c|}
\hline Gender & No & \% \\
\hline Male & 8 & 40 \\
\hline Female Total & 12 & 60 \\
\hline \multicolumn{2}{|c|}{ 20 } & $\mathbf{1 0 0}$ \\
\hline
\end{tabular}

\section{Comment}

The majority of students with disabilities were female

Table 3: Distribution by Level of Study

\begin{tabular}{|l|c|c|}
\hline Study Level & No & \% \\
\hline Bachelors & 17 & 85 \\
\hline Masters & 3 & 15 \\
\hline PHD Nil & Nil \\
\hline \multicolumn{1}{|c|}{ Total } & $\mathbf{2 0}$ & $\mathbf{1 0 0}$ \\
\hline
\end{tabular}

Comment

The majority of students with disabilities are studying for undergraduate degrees

\subsubsection{Results Analysis based on the University Processes and Activities}

Students were asked questions related to the university processes and activities from the point of entry into the university to the point of exit as shown on the interview guide on appendix 1 . These processes and activities have been used as analysis themes.

\section{a) How Students with Disabilities got to know about their Programme}

$$
\mathbf{N}=\mathbf{2 0}
$$

\begin{tabular}{|c|c|c|}
\hline Assistance rendered & No & $\%$ \\
\hline Student support services guidance & 7 & 35 \\
\hline Programme coordinator assistance & 3 & 15 \\
\hline Marketing and Communications department & 1 & 5 \\
\hline Through media and no assistance was needed & 9 & 45 \\
\hline $\begin{array}{l}\text { Total } \\
\end{array}$ & 20 & 100 \\
\hline
\end{tabular}




\section{Comment}

Students with disabilities do not experience a lot of problems in getting information about the type of degree to study. The student services department is playing a critical role in information dissemination. Many students with disabilities get information about programmes from the media like their non-disabled counterparts.

\section{b) Experiences with the Application Form}

$65 \%$ of the respondents had no problems with filing the application form. Only $1(5 \%)$ with a visual impairment said that the application form must be available in format he understand, that is Braille. $30 \%$ said that the application forms does not seek detailed information about the disability.

\section{c) The Registration Process}

Respondents did not mention any specific service rendered by the university during the registration process. The following were cited as the major challenges associated with the registration process. Note that respondents were allowed to give as many responses as possible which influenced the percentage and the frequencies.

\section{$\mathbf{N}=\mathbf{2 0}$}

\begin{tabular}{|c|c|c|}
\hline Challenges & No & $\%$ \\
\hline Inaccessibility of University Offices & 20 & 100 \\
\hline No special facilities for the disabled in fees structure and payment periods & 11 & 55 \\
\hline Reading material not always available and need be checked always & 8 & 40 \\
\hline Registration ques are too long for disability endurance & 12 & 60 \\
\hline Guards are not disability friendly when seeking special considerations & 5 & 25 \\
\hline No serious follow ups done despite indicating the disability on application form & 6 & 30 \\
\hline No scholarships to assist the disabled & 3 & 15 \\
\hline
\end{tabular}

\section{Comment}

These results show that there are many challenges experienced that pertain to the registration process especially the inaccessibility of the offices and yet students are expected to be physically present during the process.

\section{d) Reading Materials}

$15 \%$ of the respondents, one who is blind and two with albinism indicated that their visual impairments mean they expected large font or audio modules. They indicated that translating the module at their expense is difficult.

\section{e) Experience at Tutorials}

Respondents did not mention any special help they get from the region; instead, they raised the following issues

\section{$\mathbf{N}=\mathbf{2 0}$}

\begin{tabular}{|c|c|c|}
\hline Challenge/Issue & No & $\%$ \\
\hline Tutorial venues are restrictive for wheelchair users & 7 & 35 \\
\hline Only friends and class mates care on how we get to the venue & 3 & 15 \\
\hline Some tutors use language which is not disability friendly & 1 & 5 \\
\hline Do not attend & 2 & 20 \\
\hline Peers seem to have very little knowledge about disability issues & 7 & 35 \\
\hline Tutorial time too little for my disability & 4 & 20 \\
\hline Tutors do not use sign language and copy notes from friends & 1 & 5 \\
\hline Visual illustrations given exclude visual disabilities & 3 & 15 \\
\hline When carried outside skin is affected & 2 & 10 \\
\hline Do not benefit from group discussions due to my language disability & 1 & 5 \\
\hline Unclear class allocation cause rapid movement & 1 & 5 \\
\hline Toilets not disability friendly & 4 & 20 \\
\hline
\end{tabular}

\section{Comment}

From results it can be deduces that students with disabilities face a lot of tutorial related challenges. A clearer picture of the gravity of the problems is seen when we focus on specific disabilities as different disability groups face different challenges.

f) Experiences with Assignments

$(40 \%)$ of the respondents indicated that they have problems with assignments while the rest had no problems

The majority of these students indicated that they get some form of assistance from the programme coordinators but they believe more could be done as they raised the following issues 
$\mathbf{N}=\mathbf{8}$

\begin{tabular}{|l|l|}
\hline Challenge/issue & No \\
\hline Markers seem not sensitive to disability & \% \\
\hline Treated the same with late submissions even when assignment is delayed by conditions such as seizure attacks & 2 \\
\hline Difficult to get assignment interpretation & 15 \\
\hline Difficult to get assignment feedback before exams & 10 \\
\hline
\end{tabular}

\section{Comment}

Assignment marking and feedback were some of the major concerns of the respondents.

g) Examination Experiences

\begin{tabular}{|c|c|c|}
\hline Services offered /received & No & $\%$ \\
\hline Given computer by the institution to type exams & 1 & 5 \\
\hline Extra exam writing time & 8 & 40 \\
\hline Helped by student services & 3 & 15 \\
\hline Got university transport to exam venue & 1 & 5 \\
\hline Got an enunciator & 1 & 5 \\
\hline Preferential sitting given & 6 & 30 \\
\hline Given extra time after seizure attacks during exams & 2 & 10 \\
\hline
\end{tabular}

\section{Comment}

The results show that some students get assistance during the exam period. Most interviews revealed that services are not automatic but are obtained upon request and after noise making.

\begin{tabular}{|l|l|l|}
\hline Exam challenges and issues & N0 & \% \\
\hline Invigilators do not sign the instructions & 1 & 5 \\
\hline Changes may be made to question papers without my knowledge & 1 & 5 \\
\hline Exam marking seem to be done without disability consideration which lead to failure and frustration & 5 & 25 \\
\hline Invigilators, especially externals are not sensitive to disability & 8 & 40 \\
\hline Furniture not adapted to suite disability or is make shift & 8 & 40 \\
\hline Toilets not disability friendly & 4 & 20 \\
\hline
\end{tabular}

\section{Comment}

The results show that respondents experience problems such as disability sensitivity by invigilators and the unavailability of adapted furniture and toilets.

\section{h) Recommendations by Respondents}

In question two of the structured interview guide respondents were asked to give possible recommendations for improvement. The following are the major and most shared recommendations made. Note that each respondents made a number of recommendations.

\begin{tabular}{|c|c|c|}
\hline Recommendation & No & $\%$ \\
\hline Design a clear disability policy and service charter for the institution & 7 & 35 \\
\hline Make regional offices accessible to all & 15 & 75 \\
\hline Create a one stop facility for the disabled at the regional offices & 5 & 15 \\
\hline Avail modules in the format understood by specific disabilities & 4 & 20 \\
\hline Provide scholarships for students with disabilities & 5 & 25 \\
\hline Train markers and staff on disability issues & 6 & 30 \\
\hline Come up with a well equipped disability resource centre & 8 & 40 \\
\hline Boost the number of personnel in the student support department & 4 & 20 \\
\hline Make facilities at the region, tutorial and exam venues disability friendly & 7 & 35 \\
\hline Allow our relatives and friends to register on our behalf & 3 & 15 \\
\hline Need for a disability point person at the region & 5 & 25 \\
\hline Employ people with disabilities at the region & 2 & 10 \\
\hline More time to do assignments & 3 & 15 \\
\hline
\end{tabular}

\section{Discussion}

The results have shown that the university enrolls students with all types of disabilities which is in line with the philosophy of inclusive education as enshrined in international law such as the UNESCO Salamanca Statement (1994) which calls on all governments to give the highest priority to inclusive education and the UN Convention on the Rights of Persons with Disabilities (2006) which calls on all States Parties to ensure an inclusive education system at all levels. The major worry however is on the number of students with disabilities enrolled. The World Health Organisation estimates that in any given population there are about $10 \%$ people with disabilities The ZOU Harare region enroll an average of 3000 students semester and going by who standards there must be at least 300 students with disabilities in each semester. While there are 20 respondents who participated in the study the figure is slightly above this but far below the expected estimates. More worry 
comes when there are even lower numbers among those with sensory impairments such as hearing and visual impairments. A positive development from the demographic characteristics is the fact that there was gender balance among the respondents. In addition people with disabilities were studying towards higher degrees despite the lower numbers.

The results also pointed that students with disabilities got to know of their programmes through different ways. The Student Support Services and programme coordinators are doing a great job in disseminating information to students. Respondents did not point out on any difficulty in getting information related to their studies and such efforts by all need to be commented.

The application form is a very essential document as students indicate whether they have a disability or not. The majority of disabled students did not face problems with the form. The student with visual impairments indicated that there must also be form written in Braille which is very critical. What is important to note however is the fact that about $30 \%$ of the respondents feels that the information sought on the form is not detailed, Soliciting detailed disability information is very essential as it helps in service planning. The results entails that by not soliciting the critical information disability responsiveness is undermined. A good example that can be given here is that of a student with hearing impairments. The form must be specific by letting students provide more information such as whether the hearing loss is pre-lingual or post-lingual, whether it is monaural or binaural, whether its deafness or hard of hearing and whether the student can speech read. Such information is very critical for planning purposes. The current situation is so nasty that even the student support service unit get to know of disabled students from programme coordinators or when they visit in need of assistance. The proper process would be to have all application forms pass through this crucial unit such that details of students with disabilities are taken. Our experience has shown that the region does not have proper records or a central repository for students with disabilities. Such a situation greatly undermines the seriousness of the region to respond to the needs of students with disabilities.

The registration exercise is very critical for the university and the results have shown that students with disabilities do not have any special consideration during this process. The regional offices are located in third floor at a building whose lifts are not working. All the respondents $(100 \%)$ indicated that the offices are not accessible for them. This is despite the fact that registration has to be done physically by the students to reduce queries and mistakes. The university also encourages students to visit their regional offices from time to time. The current offices create a restrictive environment for those with disabilities. A lot of measures also need to be taken such as allowing those with disabilities to pay fees in cash instead of making payments to the bank first. We strongly believe that the low numbers of enrolled students with disabilities those with disabilities could be attributed to some of the issues raised our experience has shown that there is also a significant number of students with disabilities who drop their studies midway though the issue was outside the scope of the study. Attribution is given to failure to respond well to issues such as those related to the registration process. For example it is not fair to demand the physical availability of the students who use wheelchairs during registration in a building which is not accessible. Programme coordinators to some extent serve the situation when they have to go down and up the stairs to provide services to student with disabilities. In the absence of a clear disability policy the make shift activities are neither tenable nor sustainable in the long run.

The results have also indicated that there a lot of issues that need to be addressed regarding the way tutorials are conducted. Some of the major issues raised include lack of appreciation of disability by the non disabled peers and lack of movement by wheelchair users as a result of lack of ramps. Some philosophies now believe that it is better to provide e-learning tutorials to students with disabilities to avoid exclusionary practices. For example electronic communications such as threaded discussion groups, usenet discussion groups, bulletin boards and email are typically accessible to all students with disabilities. The asynchronous nature of these tools easily accommodates people who need more time to read and compose messages (http://www.washington.edu/accessit/articles?64 ).Some students (10\%)indicated that they do not even attend the tutorials. Electronic tutorials could be the best option here. However it can also be argued that e-learning widens the gap between the disabled students and their peers as lack of contact entail lack of disability understanding and appreciation. The other issue would be the accessibility of the electronic devices to the students with disabilities. The value of electronic resources is however the best option to improve the responsiveness of the university to students with disabilities. While efforts have been put in place such as the introduction of an internet lab at the region the question of accessibility of the regions comes back again.

The results have also shown that respondents had little problems when doing their assignments. About $(60 \%)$ said they had no problems with the process. Of the problems faced the respondents felt that the university is not responsive when it comes to the marking of assignments. Thus there is need for conscientisation of markers to give special considerations to the work of students with disabilities such as learning disabilities

There is an indication from the results that the university is to some extent responsive to the needs of students with disabilities during the examination process. Students are given extra time and preferential sitting. Issues that need to be addressed include the need to educate invigilators about disability issues and the need to 
make the exam venues adapted to suit disabilities especially the toilets and furniture. The marking of exams also need to consider disability.

In conclusion the Zimbabwe Open University Harare Region needs to do a lot to be able to positively respond to the needs of students with disabilities. The enrolment of these students is very insignificant $(0,67 \%)$ against world standards of $10 \%$. In most university activities and processes a lot need to be done as the help given is far much below expected standards.

\section{Recommendations}

We make the following recommendations are made

$>$ There is need for the university to reduce entry qualifications for students with disabilities such as learning disabilities

$>$ Introducing hands on programmes may help increase the enrolment of students with disabilities

> The university need to use ICT highly with disabled students to minimize their visits to seek for services

> Assignment and exam markers need to mark the work of students with disabilities with special considerations

D The regional offices must have working lifts or else moved to a place accessible by students with disabilities

$>$ There is need to design a disability policy that mandates service provision to the disabled

$>$ There must be a well resourced disability resource centre at the region

$>$ The personnel in the student support unit need to be beefed up to reduce pressure on one officer

$>$ Teaching and learning materials must be produced in the format understood by students with disabilities such as Braille and large print

\section{References}

[1]. Stodden R. A, Whelley, T., Chang, C. and Harding T. (2001) Journal of Vocational Rehabilitation 16, pp 189-198.

[2]. Disabled Persons Act [Chapter 17:01] of Zimbabwe 1996, Harare: Jongwe Printers

[3]. Dube A. and Charowa, G. 2005, "Are Disabled Peoples' Voices from both South and North Being heard in the Development process?: A Comparative analysis between the situation in South Africa, Zimbabwe, United Kingdom and Northern Europe" Disability KAR Knowledge and Research ( http://www.healthlink.org.uk/PDFs/Disabled-Peoples-Voices.pdf Accessed 2 August 2011).

[4]. Gwitimah, A. R and Khupe, W. 2008 "Promoting education \&training of disabled people (in South Africa and Lesotho)" Southern African Federation of the Disabled ((http://www.washington.edu/accessit/articles?64)

[5]. Sayini, J S and Goyal, A. 2009 Empowering the Disabled. Chandigarh: Global Media.

[6]. Choruma T. 2006 "The forgotten tribe: People with disabilities in Zimbabwe" Proggressio http://www.progressio.org.uk/sites/default/files/Forgotten-tribe.pdf Accessed 27 July 2011.

[7]. Shekhar R. (2009) Global Perspective on disabilities, Chandigarh: Global Media.

[8]. United Nations, International Day of Persons with Disabilities, 3 December 2011 http://www.un.org/disabilities/default.asp?id=1561 Accessed 4 August 2011.

[9]. (http://www.washington.edu/accessit/articles?64)

[10]. UNESCO Salamanca Statement (1994)

[11]. UN Convention on the Rights of Persons with Disabilities (2006) 